\title{
Superficial angiomyxoma of the posterior neck
}

\author{
Young Joong Hwang ${ }^{1}$, \\ Hong Won Lee', \\ Il Seok Lee', \\ Sung Gyun Jung ${ }^{1}$, \\ Hye Kyung Lee ${ }^{2}$ \\ Departments of ${ }^{1}$ Plastic and \\ Reconstructive Surgery and ${ }^{2}$ Pathology, \\ Eulji University Hospital, Daejeon, \\ Korea
}

\begin{abstract}
Superficial angiomyxoma (SA) is a rare, benign, cutaneous soft tissue tumor. It is composed of myxoid matrix and blood vessels. Herein, we report a case of a solitary SA on the posterior neck of a 6-year-old boy. An analysis of the biopsied specimen showed a prominent myxoid stroma with thin-walled, branching blood vessels, revealing the presence of an SA. SA especially that originating in the posterior neck, is rarely seen and should be considered as a differential diagnosis for a solitary mass in the posterior neck.
\end{abstract}

Keywords: Connective tissue / Myxoma / Neoplasms

\section{INTRODUCTION}

Superficial angiomyxoma (SA), also known as cutaneous myxoma, is a rare benign, cutaneous soft tissue tumor composed of myxoid matrix containing numerous blood vessels. SA was first described by Carney et al. in 1985, and it can appear as solitary or multiple lesions associated with the Carney complex [1,2]. With an incidence of approximately $0.008 \%-3 \%$, SA is more common in men, usually occurring in the trunk, limb, and genital areas [3,4]. The recommended treatment for SA is surgical wide excision, although local recurrence remains possible even with this treatment [4]. SA should not be confused with aggressive angiomyxomas, which are deeper myxomas with high vascular proliferation. Aggressive angiomyxomas occur more frequently in women and have a predisposition for the vulvar region with a higher recurrence rate [1,4]. SA of the posterior neck has not been reported in the Republic of Korea. Herein, we report the case of a 6-year-old boy with solitary SA of the posterior neck detected with histological analysis and verified with literature references.

Correspondence: Sung Gyun Jung

Department of Plastic and Reconstructive Surgery, Eulji University Hospital,

95 Dunsanseo-ro, Seo-gu, Daejeon 35233, Korea

E-mail: psjung111@gmail.com

Received November 17, 2020 / Revised February 12, 2021 / Accepted February 19, 2021

\section{CASE REPORT}

A 6-year-old boy visited our hospital with an asymptomatic mass on the posterior neck that developed gradually over a 1-month period. There were no specific findings in his past or family history. The initial physical examination showed a smooth, elevated surface of a round solid mass on the posterior neck with a size of $2.0 \times 2.0 \mathrm{~cm}$. Because of the patient's age and the location of the mass, the differential diagnosis was pilomatricoma, dermoid cyst, and lymph node hyperplasia. The patient underwent a complete resection without prior ultrasonography or neck computed tomography, and a biopsy was performed to develop an accurate diagnosis and treatment (Figs. 1, 2). The completely excised mass was $1.5 \times 1.5 \mathrm{~cm}$ in size and had a bright yellow color and translucent surface. The tumor was limited to the superficial subcutaneous layer, and the surgical margins were clear and well-defined. Histopathologic examination with hematoxylin and eosin staining revealed abundant myxoid stroma with low cellularity. Higher magnification showed uniform, spindle-shaped tumor cells with prominent, thin-walled, branching blood vessels, and neutrophil infiltration. Immunohistochemical staining was performed to make a differential diagnosis of superficial myxoid lesions. Staining with CD-34 was positive, and S-100 was negative (Fig. 3). Based on these clinical and histological findings, the mass was diagnosed as SA. The patient has not experienced recur- 


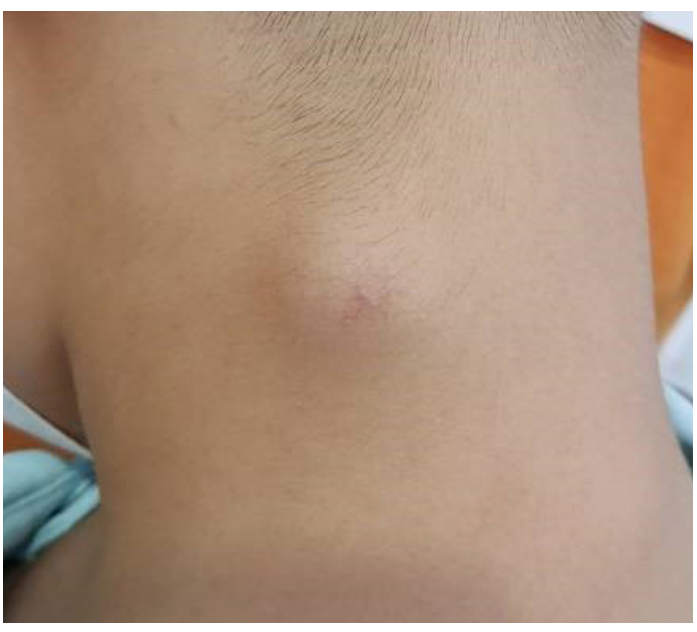

Fig. 1. Preoperative photograph. A solitary mass on the posterior neck of a 6-year-old boy.
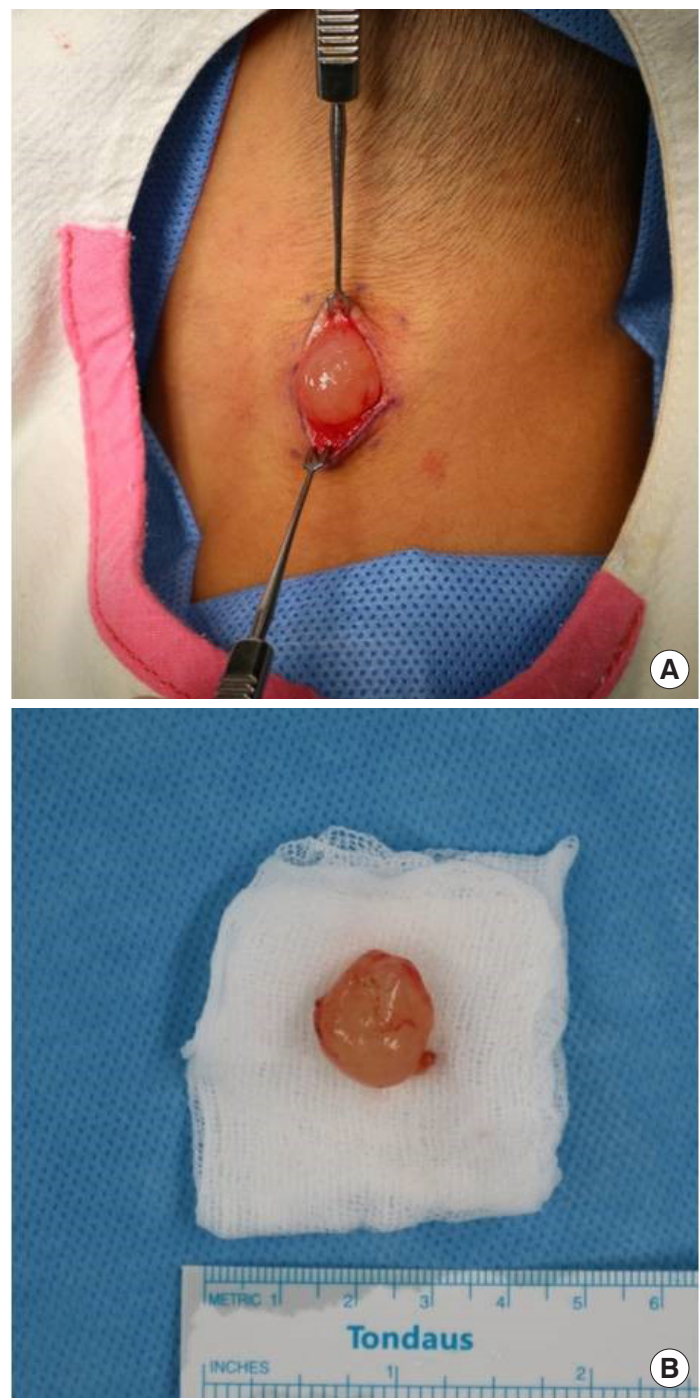

Fig. 2. Intraoperative photographs. (A) Intraoperative image showed a mass located close to skin. (B) The resected specimen measured approximately $1.5 \times 1.5 \mathrm{~cm}$, with well-defined margin.
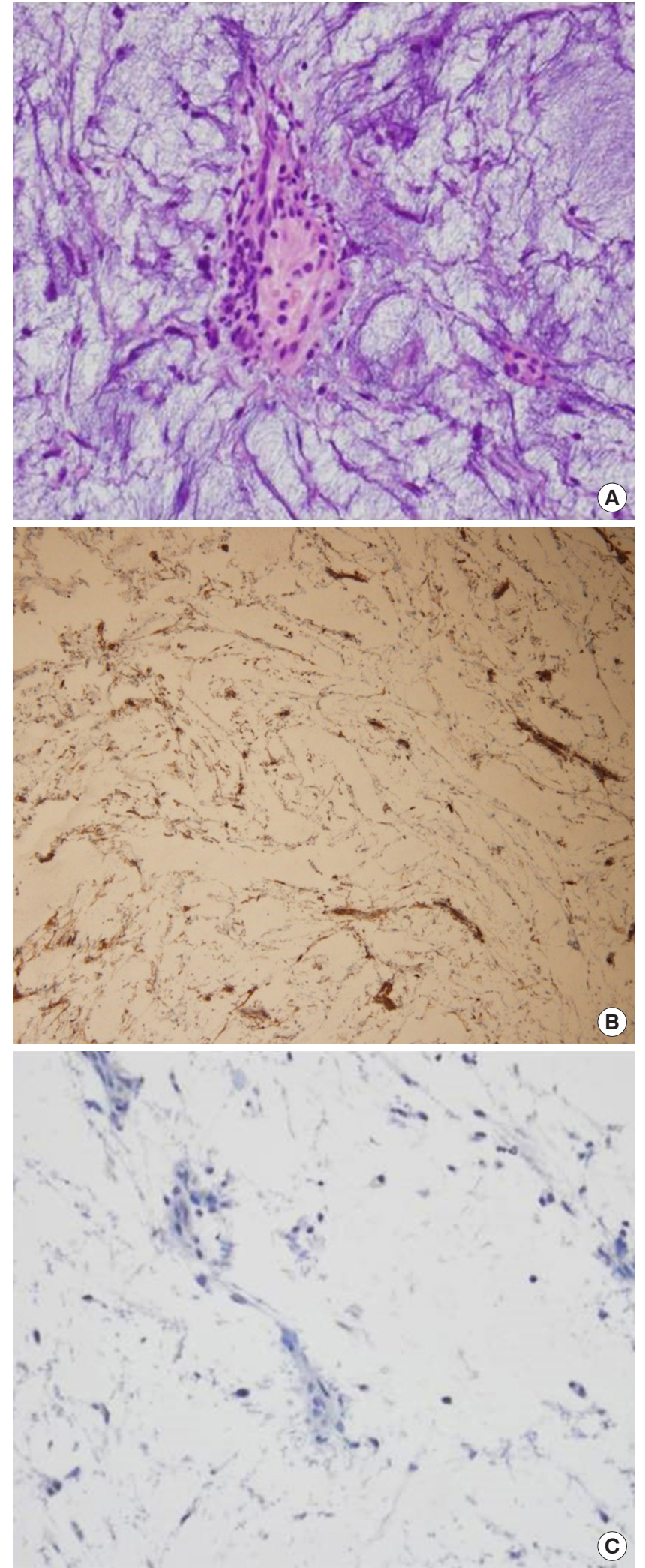

Fig. 3. Photomicrographs of the specimen. (A) The specimen was a well-bounded mass with uniform, spindle-shaped tumor cell in prominent myxoid stroma $(\mathrm{H} \& \mathrm{E}, \times 400)$. Immunohistochemical stain was positive for $\mathrm{CD}-34(\mathrm{~B}, \times 400)$ and negative for S-100 protein $(C, \times 100)$. 
rence or metastasis to date, and we have continued to follow-up with him for 1 year.

\section{DISCUSSION}

SA was initially described by Carney et al. in 1985, in association with an autosomal dominant disorder known as the "Carney complex" [1]. This complex affects multiple organs, such as the heart, breasts, and skin, and usually comprises multiple myxoid skin tumors and cardiac myxomas. Endocrine overactivity, such as Cushing syndrome and acromegaly, can also be associated with SA due to pigmented adrenocortical tumors and pituitary adenomas [2].

Allen et al. [5] reported cases of SA occurring without the Carney complex and based on the clinicopathological and immunohistochemical features of SA, Calonje et al. [6] reported that SA and the Carney complex are independent of each other. $\mathrm{SA}$ is a rare soft tissue benign tumor usually found in the trunk, limbs, head, lower extremities, and genitalia. The local recurrence rate is $30 \%-40 \%$, but malignant changes or distant metastases have not been reported.

If patients with endocrine overactivity show SA at multiple sites, especially in the external ears or eyelids, the surgeon must consider the possibility of the Carney complex. Thus, a thorough patient history assessment, physical examination, and heart sonography must be performed [7].

In the present study, the patient visited our clinic with a single, soft, slightly fixed, benign-looking mass with a clear margin and a clinical differential diagnosis of benign soft tissue tumor, such as a pilomatricoma, dermoid cyst, or lymph node hyperplasia. However, through postoperative pathologic and immunohistochemical examinations, we determined that the mass was an SA.

Considering the rarity of SA, subcutaneous masses of this type are infrequently predicted accurately, as surgeons usually predict it as a common benign soft tissue tumor. Although surgeons usually perform simple excisions and biopsies, incomplete surgical resections and deep invasions of SA increase the recurrence rate $[1,3,5,6,8-10]$. Usually, SA have a poorly defined margin [11], which can lead to incomplete removal and local recurrence of the tumor. Wide excision is recommended to prevent local recurrence of SA, and surgical resection is recommended, including the margins of normal-appearing tissue $[4,12]$. However, in our case, the tumor had a well-defined margin. We did not consider performing a wide excision because complete resection of the tumor was achieved. We suggest that plastic surgeons should consider additional surgical treatments in case of incomplete excision of the SA.

\section{NOTES}

\section{Conflict of interest}

No potential conflict of interest relevant to this article was reported.

\section{Ethical approval}

The study was approved by the Institutional Review Board of Samsung Medical Center (IRB No. 2020-08-010-002) and performed in accordance with the principles of the Declaration of Helsinki. Written informed consent was obtained.

\section{Patient consent}

The patient's guardian provided written informed consent for the publication and the use of patient images.

\section{ORCID}

Young Joong Hwang https://orcid.org/0000-0001-7349-7132 Hong Won Lee https://orcid.org/0000-0002-0338-4391

Il Seok Lee https://orcid.org/0000-0002-8313-2513

Sung Gyun Jung https://orcid.org/0000-0002-7768-9972

Hye Kyung Lee https://orcid.org/0000-0003-4967-7816

\section{Author contribution}

Conceptualization: SGJ. Data curation: HWL, HKL. Project administration: HWL, SGJ. Investigation: HWL. Supervision: YJH, SGJ, HKL. Writing - original draft: HWL, ISL. Writing review \& editing: YJH, HWL, ISL, SGJ. Approval of final manuscript: all authors.

\section{REFERENCES}

1. Carney JA, Gordon H, Carpenter PC, Shenoy BV, Go VL. The complex of myxomas, spotty pigmentation, and endocrine overactivity. Medicine (Baltimore) 1985;64:270-83.

2. Allen PW. Myxoma is not a single entity: a review of the concept of myxoma. Ann Diagn Pathol 2000;4:99-123.

3. Ali N, Child CS, Michaelides M, Olver JM. Recurrence of a rare skin tumour: superficial angiomyxoma in the eyelid. Can J Ophthalmol 2011;46:205-6.

4. Lee CC, Chen YL, Liau JY, Chen CA, Cheng WF. Superficial angiomyxoma on the vulva of an adolescent. Taiwan J Obstet Gynecol. 2014;53:104-6.

5. Allen PW, Dymock RB, MacCormac LB. Superficial angiomyxomas with and without epithelial components. Report of 30 tumors in 28 patients. Am J Surg Pathol 1988;12:519-30.

6. Calonje E, Guerin D, McCormick D, Fletcher CD. Superficial angiomyxoma: clinicopathologic analysis of a series of distinc- 
tive but poorly recognized cutaneous tumors with tendency for recurrence. Am J Surg Pathol 1999;23:910-7.

7. Kennedy RH, Waller RR, Carney JA. Ocular pigmented spots and eyelid myxomas. Am J Ophthalmol 1987;104:533-8.

8. Heymans O, Medot M, Hermanns-Le T, Pierard G, Fissette J, Lahaye T. Recurrent pleomorphic solitary angiomyxoma of the face. Dermatology 1999;198:195-7.

9. Kahn SL, Juhl ME, Sidiropoulos M, Guitart J, Antonijevic S, Krunic AL. Angiomyxoma of the nasal dorsum treated by Mohs surgery. Australas J Dermatol 2016;57:e8-10.
10. Yun YI, Lee KS, Khwarg SI, Kim N. Rare case of isolated superficial angiomyxoma of the eyelid. Korean J Ophthalmol 2020;34:262-4.

11. Yuen HK, Cheuk W, Luk FO, Wat CS, Auyeung KC, Lam DS. Solitary superficial angiomyxoma in the eyelid. Am J Ophthalmol 2005;139:1141-2.

12. Kim SM, Kim CK, Kim SH, Lee MC, Kim JN, Choi HG, et al. Myxoma arising from the parotid gland. Arch Craniofac Surg 2019;20:186-90. 